\title{
Simulation of a Free Surface Flow over a Container Vessel Using CFD
}

\author{
Krishna Atreyapurapu ${ }^{1}$ \\ M.E Student \\ Dept. of Marine Engineering \\ A U C E., Visakhapatnam \\ India
}

\author{
Bhanuprakash Tallapragada ${ }^{2}$ \\ Professor \\ Dept. of Marine Engineering \\ A U C E., Visakhapatnam \\ India
}

\author{
Kiran Voonna ${ }^{3}$ \\ Manager \\ CD-Adapco \\ Bangalore \\ India
}

\begin{abstract}
Practical application of Computational Fluid Dynamics (CFD) for predicting flow pattern around a ship hull and calculation of total resistance has been a topic of great interest for researchers in ship hydrodynamics. Today, several CFD tools have been developed to analyse and capture the free surface around a ship. The flow problem is rich in complexity and poses many challenges during simulation. Many mesh sizes were tried during modelling with Realizable $k-\varepsilon$ and shear stress Transport (SST) $k-\omega$ turbulent models. The free surface wave pattern and the total resistance (shear and pressure resistances) were calculated. The effects of sinkage and trim were also studied using STAR-CCM+ software implementing a Reynolds averaged Nervier stokes (RANS) equation solver with free-surface capabilities. Predicted results were compared against empirical data showing good agreement. The method is found to be stable and is believed to predict the resistance for any ship with or without trim and sinkage.
\end{abstract}

Key words: Turbulent Models, Free-surface flow, ship resistance, trim and sinkage

\section{INTRODUCTION}

The "energy efficient ship" is a topic that has dominated the shipping world for the last 6 years due to the sudden hike in fuel prices in 2008. Most of the energy consumed in a ship is for propulsion which accounts for as much as $90 \%$ in some large ships while in some smaller ships, propulsion energy consumption accounts for $60 \%$ of the fuel consumption. Reducing the propulsive power requirement by reducing the total resistance will lead to savings in fuel consumption. Thus it is evident that the total resistance of a ship be determined as accurately as possible so that accurate fuel consumption can be determined and eventually efforts can be put reduce the fuel consumption.

Once the ship lines are generated, we require some means by which the ship resistance is determined. Experimental techniques such as towing tank experiments are costly and time consuming. If the resistance is found to be high, modifications to the model cannot be done easily. Thus it is evident that recourse to numerical techniques for predicting the resistance is to be taken made. With the progress in CFD and a series of dedicated validation workshops and research projects after the year 2000, the numerical CFD codes now can comfortably capture both the viscous and pressure resistances at one go without having to worry about scale effects.

The past twenty years revolutionized to some extent the way ships were designed and performance tested. The credit goes to the use of high speed computers and sophisticated software's which made numerical computations possible. Innovation was made more possible because of increased knowledge provided earlier in the design stage by computer design and simulations. One of the tools that have been more and more included in ship design is Computational Fluid Dynamics (CFD). Traditionally ship performances have been found from empirical hull series and propeller series to estimate power and performance in conceptual design. Now CFD can provide knowledge and results that was previously provided by model hull series.

\subsection{Computational Fluid Dynamics in Ship Design}

Computational Fluid Dynamics (CFD) is widely seen as a key technology in shipping industry for predicting the performance coefficients that help in determining the final ship shape. CFD denotes techniques solving fluid dynamics equations numerically, usually involving significant computational effort. Colloquially, CFD for resistance and propulsion analyses is sometimes referred to as the "numerical model basin" or the "numerical towing tank" or "numerical sea trials". CFD codes solve RANS (Reynolds-averaged Navier-Stokes) equations employing fine grids and advanced turbulence models. These are called high-fidelity FD codes. The objective of Computational Fluid Dynamics (CFD) in naval engineering applications is to accurately simulate the behaviour of full scale ships in real operating conditions. The role of Computation Fluid Dynamics acquires a particular relevance in those applications where optimal design is critical.

Computational Fluid Dynamics is a numerical process where the basic governing equations of fluid flow are attempted to be solved. The three conservation equations are the mass conservation (continuity equation), momentum conservation (Navier-Stokes equations) and energy equation (if buoyancy effects need to be considered). The highest efforts are placed in solving the NS equations while simultaneously checking that the continuity equation is satisfied. This NS equation is a coupled, non-linear partial differential equation that describes the flow in and out of a control volume. Equations (1) and (2) show the Reynolds Averaged Navier Stokes equation and an equation (3) is the volume fraction transport equation.

$$
\begin{aligned}
& \frac{\partial\left(\rho \mathrm{U}_{\mathrm{i}}\right)}{\partial \mathrm{t}}+\frac{\partial\left(\rho \mathrm{U}_{\mathrm{i}} \mathrm{U}_{\mathrm{J}}\right)}{\partial \mathrm{x}}=-\frac{\partial \mathrm{P}}{\partial \mathrm{x}_{\mathrm{j}}}+\frac{\partial \mathrm{P}}{\partial \mathrm{x}_{\mathrm{j}}}\left[\mu\left(\frac{\partial \mathrm{U}_{\mathrm{i}}}{\partial \mathrm{x}_{\mathrm{j}}}+\frac{\partial \mathrm{U}_{\mathrm{J}}}{\partial \mathrm{x}_{\mathrm{J}}}\right)\right]- \\
& \frac{\partial\left(\rho \mathrm{u}^{\prime}{ }_{\mathrm{i}}^{\prime}{ }_{\mathrm{j}}\right)}{\partial \mathrm{x}}+\mathrm{f}_{\mathrm{i}} \\
& \frac{\partial U_{i}}{\partial x_{i}}=0
\end{aligned}
$$




$$
\frac{\partial C}{\partial t}+\frac{\partial\left(c U_{j}\right)}{\partial x_{j}}=0
$$

The Volume friction $\mathrm{c}$ is defined as $\left(\mathrm{V}_{\text {air }} / \mathrm{V}_{\text {total }}\right)$ and the fluid density, $\rho$, and viscosity, $\mu$, are calculated as $\rho=$ $\rho_{\text {air }} c+\rho_{\text {water }}(1-c)$ and $\mu=\mu_{\text {air }} c+\mu_{\text {water }}(1-c)$ External forces applied to the fluid which include buoyancy forces due to differences in density and momentum sources are represented as $f_{i}$

\section{NUMERICAL MODEL}

Table1 - Parameters used in the computation

\begin{tabular}{|c|c|}
\hline \multicolumn{2}{|c|}{ Main particular of Container Ship } \\
\hline Length of water Line (L) & $123.03 \mathrm{~m}$ \\
\hline Breadth $(\mathrm{B})$ & $19 \mathrm{~m}$ \\
\hline Draft deign $\left(\mathrm{T}_{\mathrm{F}}, \mathrm{T}_{\mathrm{A}}\right)$ & $6.5 \mathrm{~m}$ \\
\hline Displacement & 11015.823 tonne \\
\hline Displacement volume & $10833 \mathrm{~m}^{3}$ \\
\hline Property & Mesh \\
\hline Type of mesh & $\begin{array}{l}\text { Unstructured } \\
\text { (Trimmed ) }\end{array}$ \\
\hline No of elements & 2.7 \\
\hline$y+$ on the hull & Approximately 1.2-130 \\
\hline Domain Physics & $\begin{array}{l}\text { Homogeneous } \\
\text { water/Air multiphase, } \\
\text { Realizable k- } \varepsilon \text { and SST } \\
\text { k- } \omega \text { Turbulent Model }\end{array}$ \\
\hline \multicolumn{2}{|l|}{ Initial Physics: } \\
\hline Pressure & Hydrostatic pressure \\
\hline Volume Fraction & $\begin{array}{l}\text { Air } \\
\text { Volume Fraction of } \\
\text { lighter Fluid } \\
\text { Water } \\
\text { Volume Fraction of } \\
\text { Heaver Fluid. }\end{array}$ \\
\hline Gravity & In $\mathrm{Z}$ direction $-9.81 \mathrm{~m} / \mathrm{s}$ \\
\hline \multicolumn{2}{|l|}{ Boundary Physics: } \\
\hline Inlet & $\begin{array}{l}\text { velocity at that Froude } \\
\text { Number with defined } \\
\text { volume fraction }\end{array}$ \\
\hline Outlet & Pressure outlet \\
\hline Hull & $\begin{array}{l}\text { Wall with No slip } \\
\text { condition }\end{array}$ \\
\hline Symmetry plane & $\begin{array}{l}\text { Along the center line of } \\
\text { hull }\end{array}$ \\
\hline \multicolumn{2}{|l|}{ Fluid Properties } \\
\hline Density of water & $1024.57 \mathrm{~kg} / \mathrm{m}^{3}$ \\
\hline Dynamic viscosity & 0.001008 pa-s \\
\hline
\end{tabular}

Simulations are performed using Star-CCM+9.04.011 version which is a commercial Finite Volume Code. This software uses gradients to improve accuracy and robustness in unstructured meshes. The simulation is run for a physical time of $200 s$ using "Implicit Unsteady Segregated Flow Solver". The time step is calculated based of Courant number. Table 1 shows the physical parameter along with Main Particular of the Container Ship and Fluid properties used for this study.

\section{MESHING TECHNIQUE}

The meshing model used in STAR-CCM+ gives a trimmed hexahedral cell shape based core mesh. One of the desirable attributes of these meshing models is that curvature and proximity refinement is done based upon surface cell size. It utilizes a template mesh constructed from hexahedral cells from which it cuts or trims the core mesh based on the starting input surface. Areas of curvature and close proximity are refined based upon the surface cell sizes. The resulting mesh is composed predominantly of hexahedral cells with trimmed cells next to the surfaces. Trimmed cells are polyhedral cells that can be described as hexahedral cells with one or more corners and/or edges cut-off. The domain dimensions were chosen as for the best Practices available i.e.

$\begin{array}{ll}\text { Forward } & \text { Length of Ship } \\ \text { Stern } & \text { 2.5 times Length of Ship } \\ \text { Depth } & \text { Length of Ship } \\ \text { Top } & \text { 0.5 times Length of Ship }\end{array}$

To vary the mesh density along the domain volumetric controls were built which work in conjunction with volume shapes. These volume shapes encompass more computationally demanding and computationally important spaces of the mesh, e.g., the space around the bow and around the stern, as well as the space around the free surface up to the height of the generated waves. Through the volumetric controls, those spaces, covered by the shapes, were specified to have a more refined mesh.

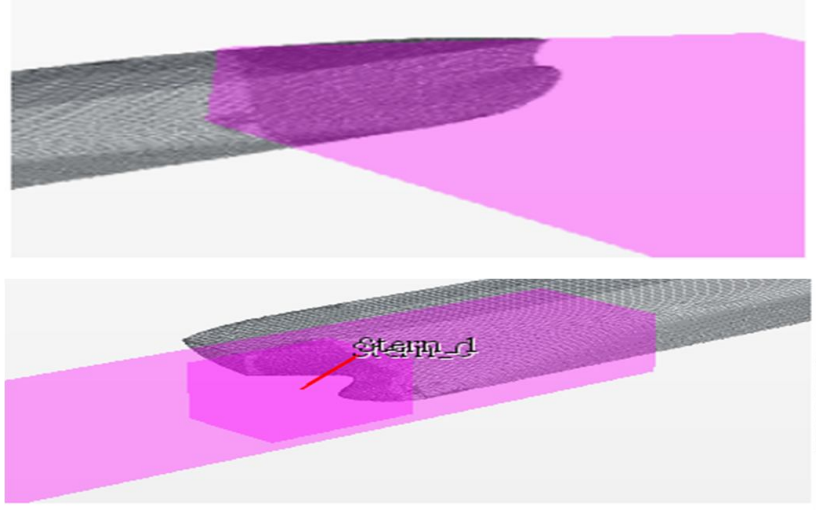

Figure 1 - Volumetric Refinement at Bow and Stern to Control the Mesh Density

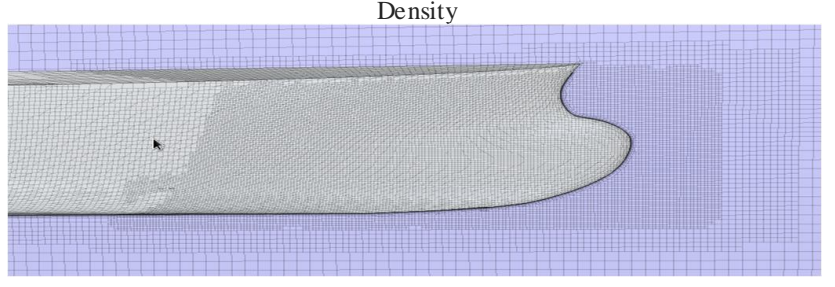




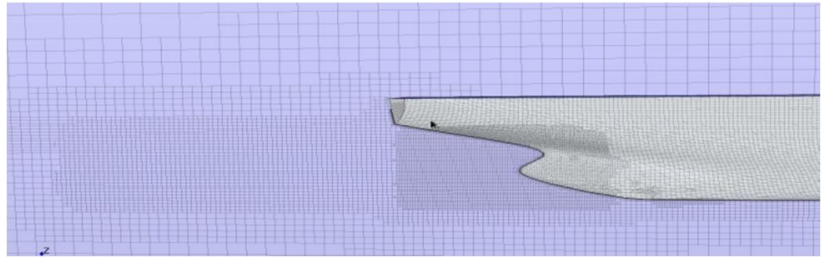

Figure 2 - Volume Mesh with Volumetric Refinement at Bow and Stern

To evaluate how the number of elements within the mesh affects the solution a grid independence study is carried out at $F n=0.24$, corresponding to $R e=9.9 \times 10^{8}$. For RANS analysis four grids are generated: a coarse grid of 2.1 Million, two medium grids of 2.7 (medium 1) and 4.7 (medium 2) Million cells and a fine grid of 5.7 Million cells. Two turbulent models considered for the study are Realizable $K-$ $\varepsilon$ and SST $k-\omega$. In both the models height of the first layer of the cells on the hull walls are of $3.5 \times 10^{-6}$ for all the grids. This allowed to obtain $y^{+}<130$ on the whole hull. This wall $y^{+}$is also used to evaluate generated mesh in each case along with the Courant number, which is scalar and dimensionless.

TABLE 2 - MESH INDEPENDENT STUDY WITHOUT TRIM AND SINKAGE FOR REALIZABLE $\mathrm{K}-\epsilon$ TURBULENT MODEL

\begin{tabular}{|c|c|c|c|}
\hline $\begin{array}{c}\text { Cell } \\
\text { Count } \\
\text { (Million) }\end{array}$ & $\begin{array}{c}\text { Total } \\
\text { Resistance } \\
(\mathbf{k N})\end{array}$ & $\begin{array}{c}\text { Difference } \\
\text { Percentage }\end{array}$ & $\begin{array}{c}\text { Computational } \\
\text { Time (Hours) }\end{array}$ \\
\hline 2.1 & 343.21 & $2.54 \%$ & 8.7 \\
\hline 2.7 & 346.24 & $3.44 \%$ & 11.37 \\
\hline 4.7 & 347.07 & $3.69 \%$ & 20.13 \\
\hline 5.7 & 365.04 & $9.06 \%$ & 24.3 \\
\hline
\end{tabular}

TABLE 3 - MESH SENSITIVITY STUDY WITHOUT TRIM AND SINKAGE FOR SST $k-\omega$ TURBULENCE MODEL

\begin{tabular}{|c|c|c|c|}
\hline $\begin{array}{c}\text { Cell } \\
\text { Count } \\
\text { (Million) }\end{array}$ & $\begin{array}{c}\text { Total } \\
\text { Resistance } \\
(\mathbf{k N})\end{array}$ & $\begin{array}{c}\text { Difference } \\
\text { Percentage }\end{array}$ & $\begin{array}{c}\text { Computational } \\
\text { Time (Hours) }\end{array}$ \\
\hline 2.1 & 332.48 & $-0.66 \%$ & 8.25 \\
\hline 2.7 & 336.11 & $0.42 \%$ & 10.45 \\
\hline 4.7 & 343.37 & $2.59 \%$ & 19.22 \\
\hline 5.7 & 357.61 & $6.84 \%$ & 23.82 \\
\hline
\end{tabular}

Table 2 and 3 shows the total resistance for various mesh sizes. As we can see with the number of cells increasing from 2.1 $\mathrm{M}$ to $5.7 \mathrm{M}$, the computational time has increased from 8 hours to 25 hours i.e. around $300 \%$ increase in computational time. The improvement in the total resistance is not very appreciable which indicates that the solution is more or less independent of mesh. The improvement can be seen to be around $6 \sim 7 \%$ at a cost of $300 \%$ increase in time. For all further analyses, we considered an optimal mesh of 2.7 million cells. The percentage difference in total resistance is around $3.4 \%$ in Realizable $k-\epsilon$ turbulent model whereas it is $0.42 \%$ in case of SST $k-\omega$ turbulent model with a slight increase in computational time of $25 \%$ compared to 2.1 million cells

\section{RESULTS AND DISCUSSIONS}

Once the wall $y^{+}$and courant number are in acceptable range the predicted resistance along the hull was obtained correctly. The solver is run for velocities of $5.5 \mathrm{~m} / \mathrm{s}$ to $8.5 \mathrm{~m} / \mathrm{s}$ with an interval of $1 \mathrm{~m} / \mathrm{s}$ giving Froude numbers of 0.15 to 0.24 . The predicted CFD total resistance including shear and pressure resistance for all Froude numbers considered are given in detail with and without trim and sinkage. Figure 3 and 4 shows the wall $\mathrm{y}+$ and Courant number for a Container ship which is considered in this work.

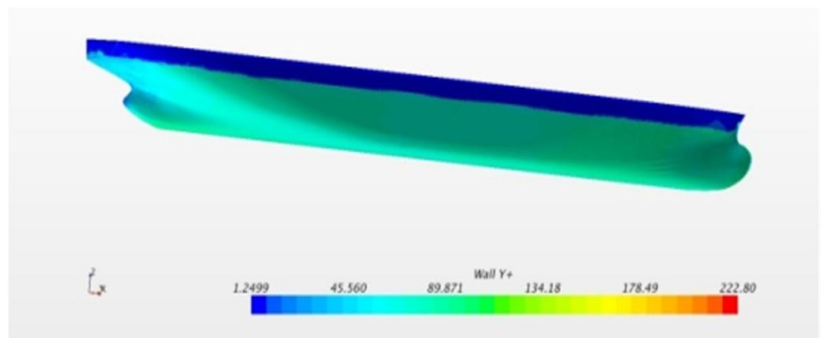

Figure 3 - The wall $\mathrm{Y}^{+}$Value for Container Vessel at $\mathrm{Fn}=0.25$

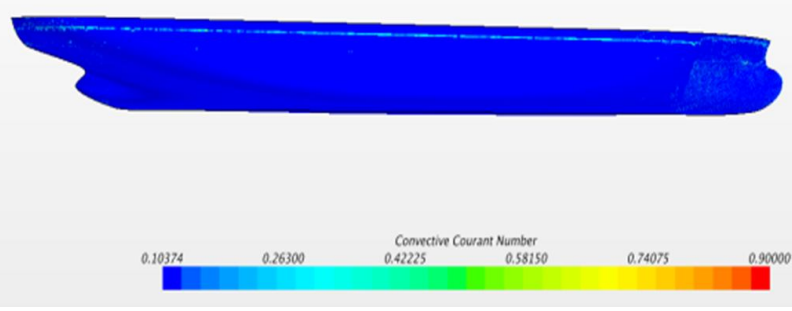

Figure 4 - Courant Number for Simulated Container Vessel with Free Surface

TABLE 4 - RESISTANCE FOR DIFFERENT FROUDE NUMBER FOR A REALIZABLE $\mathrm{K}-\epsilon$ TURBULENT MODEL WITHOUT TRIM \& SINKAGE MESH SELECTED IS 2.7M

\begin{tabular}{|c|c|c|c|}
\hline $\begin{array}{c}\text { Froude } \\
\text { number } \\
\text { (Fn) }\end{array}$ & $\begin{array}{c}\text { Predicted } \\
\text { (CFD) Total } \\
\text { Resistance } \\
\text { (kN) }\end{array}$ & $\begin{array}{c}\text { Total } \\
\text { Resistance } \\
\text { (Using } \\
\text { Holtrop } \\
\text { Mennen } \\
\text { Method) kN }\end{array}$ & $\begin{array}{c}\text { \% difference in } \\
\text { Total Resistance }\end{array}$ \\
\hline 0.15 & 88.68 & 99.89 & $-11.22 \%$ \\
\hline 0.18 & 134.30 & 145.05 & $-7.41 \%$ \\
\hline 0.21 & 207.78 & 211.51 & $-1.76 \%$ \\
\hline 0.24 & 346.24 & 334.70 & $3.44 \%$ \\
\hline
\end{tabular}


TABLE 5 - RESISTANCE FOR DIFFERENT FROUDE NUMBER FOR A SST $\mathrm{K}-\omega$ TURBULENT MODEL WITHOUT TRIM \& SINKAGE MESH SELECT IS $2.7 \mathrm{M}$

\begin{tabular}{|cc|c|c|}
\hline $\begin{array}{c}\text { Froude } \\
\text { number } \\
(\mathbf{F n})\end{array}$ & $\begin{array}{c}\text { Predicted } \\
\text { (CFD) Total } \\
\text { Resistance } \\
(\mathbf{k N})\end{array}$ & $\begin{array}{c}\text { Total } \\
\text { Resistance } \\
\text { (Using Holtrop } \\
\text { Mennen } \\
\text { Method) } \mathbf{k N}\end{array}$ & $\begin{array}{c}\text { \% difference } \\
\text { in Total } \\
\text { Resistance }\end{array}$ \\
\hline 0.15 & 95.40 & 99.89 & $-4.49 \%$ \\
\hline 0.18 & 133.44 & 145.05 & $-8.00 \%$ \\
\hline 0.21 & 198.5 & 211.51 & $-6.15 \%$ \\
0.24 & 336.11 & 334.70 & $1.02 \%$ \\
\hline
\end{tabular}

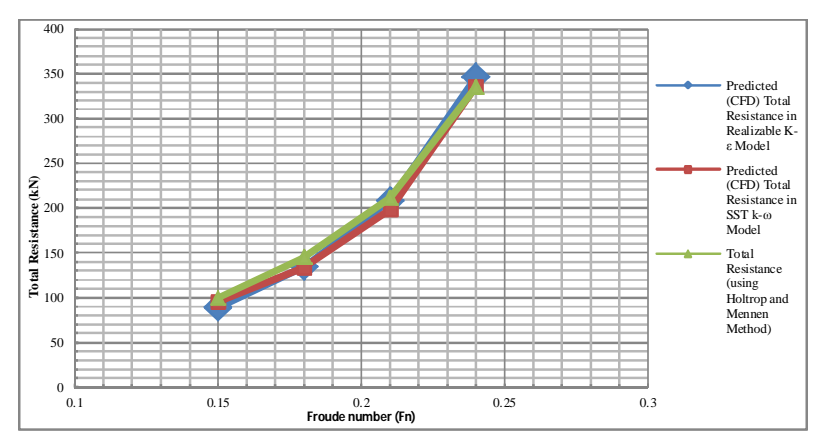

Figure 5 - Predicted Total Resistance v/s Empirical Total Resistance

Table 4 and 5 shown above outlines the resistance values for various Froude numbers in the region $F n=0.15$ to 0.24 with cell count of $2.7 \mathrm{M}$. Figure 5 shows the Total resistance variation without trim and sinkage with Froude number for the two turbulent models considered. The results are compared with Holtrop and Mennen Method for all the Froude numbers considered it can be seen that the numerically predicted results using the two turbulence models are close to the empirical method given by Holtrop and Mennen but at $F n=0.24 S S T k-\omega$ turbulent model has predicted more accurate results than realizable $k-\varepsilon$ turbulent model in comparison with Holtrop and Mennen method. Effect of trim and sinkage on resistance was carried out by simulating with a dynamic fluid body interaction technique which is capable of controlling the Degree of freedom in $\mathrm{Z}$ translation and $Y$ rotation. Table 6 and 7 show the total resistance for various Froude number with trim and sinkage in Realizable $k-\varepsilon$ and SST $k-\omega$ turbulent models respectively.

TABLE 6 - RESISTANCE FOR DIFFERENT FROUDE NUMBER FOR A REALIZABLE $\mathrm{K}-\epsilon$ TURBULENT MODEL WITH TRIM \& SINKAGE MESH SELECT IS $2.7 \mathrm{M}$

\begin{tabular}{|c|c|c|c|}
\hline $\begin{array}{c}\text { Froude } \\
\text { number } \\
(\mathbf{F n})\end{array}$ & $\begin{array}{c}\text { Predicted (CFD) } \\
\text { Total Resistance } \\
(\mathbf{k N})\end{array}$ & Trim (Deg) & Sinkage (m) \\
\hline 0.15 & 94.24 & 0.043 & -0.091 \\
0.18 & 140.48 & 0.094 & -0.135 \\
\hline 0.21 & 188.16 & 0.106 & -0.184 \\
\hline 0.24 & 338.76 & 0.109 & -0.266 \\
\hline
\end{tabular}

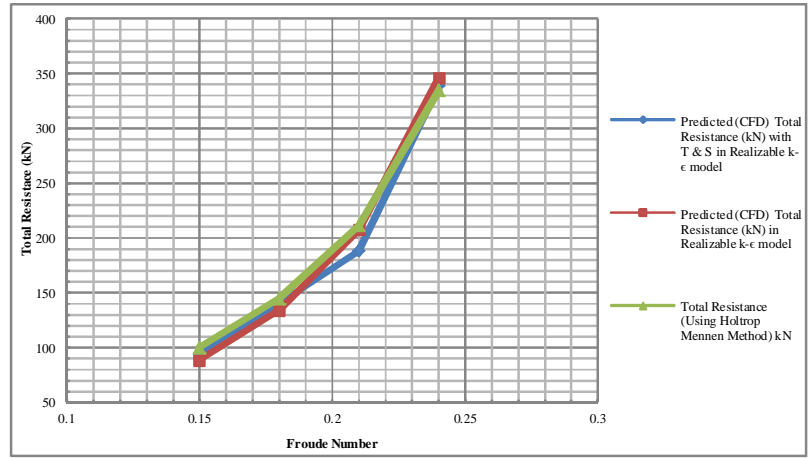

Figure 6 - Predicted Total Resistance with and without Trim and Sinkage in Realizable k $-\epsilon$ Turbulent Model

It can be seen from the above graph that the total resistance with trim and sinkage is slightly less than of total resistance without trim and sinkage.

TABLE 7 - RESISTANCE FOR DIFFERENT FROUDE NUMBER FOR A SST $\mathrm{k}-\omega$ TURBULENT MODEL WITH TRIM \& SINKAGE MESH SELECT IS $2.7 \mathrm{M}$

\begin{tabular}{|c|c|c|c|}
\hline $\begin{array}{c}\text { Froude } \\
\text { number } \\
\mathbf{( F n )}\end{array}$ & $\begin{array}{c}\text { Predicted (CFD) } \\
\text { Total Resistance } \\
(\mathbf{k N})\end{array}$ & $\begin{array}{c}\text { Trim } \\
(\mathbf{D e g})\end{array}$ & Sinkage (m) \\
0.15 & 94.12 & 0.044 & -0.090 \\
\hline 0.18 & 127.96 & 0.078 & -0.128 \\
\hline 0.21 & 210.71 & 0.097 & -0.188 \\
0.24 & 362.10 & 0.095 & -0.258 \\
\hline
\end{tabular}

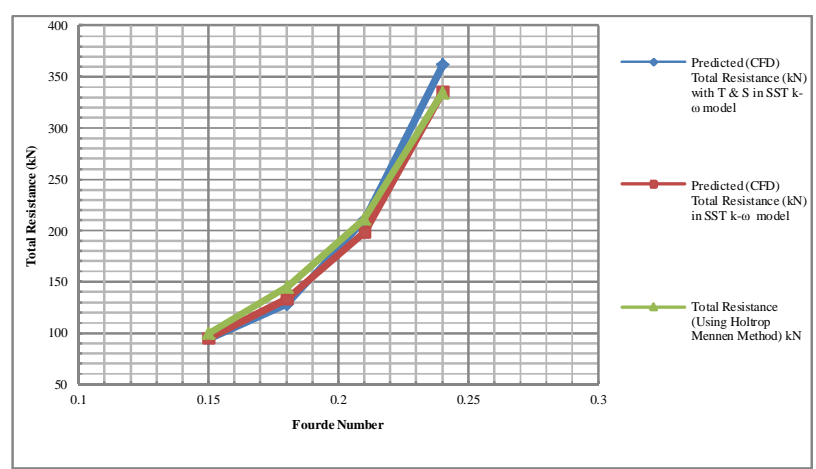

Figure 7 - Predicted Total Resistance with and without Trim and Sinkage in SST $\mathrm{k}-\omega$ Turbulent Model

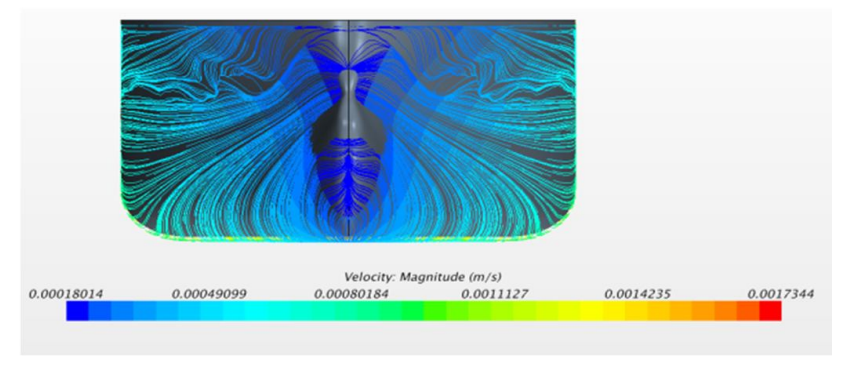

Figure 8 - Streamlines for the Fn $=0.24$ at Bow Part 


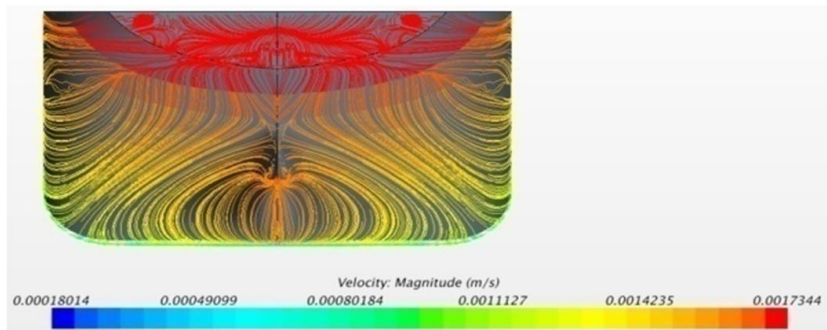

Figure 9 - Streamlines for the $F n=0.24$ at Stern Part

Figures 8 and 9 shows the streamlines at bow and stern part for $F n=0.24$. The streamlines are smooth indicating that the bow and stern forms were nicely faired and no separation has occurred.

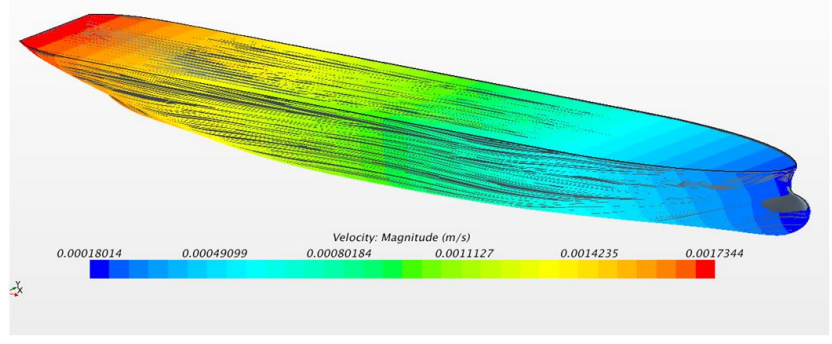

Figure 10 - Streamlines along the Length of Vessel at Fn $=0.24$

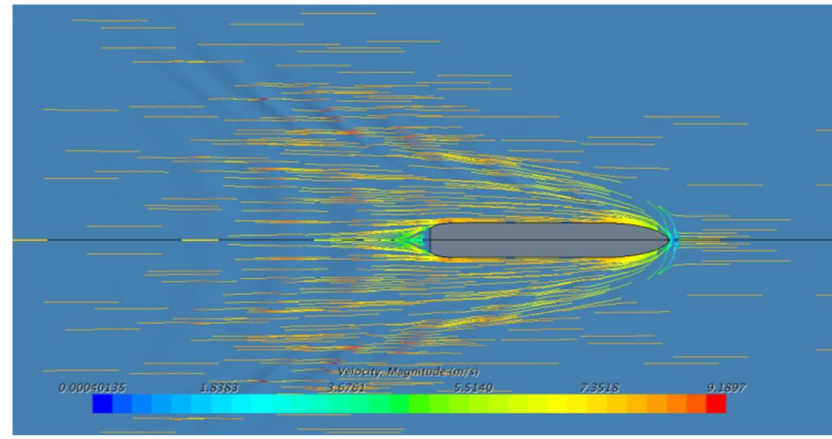

Figure 11 - Streamline Along With The Wake Pattern for the Fn $=0.24$

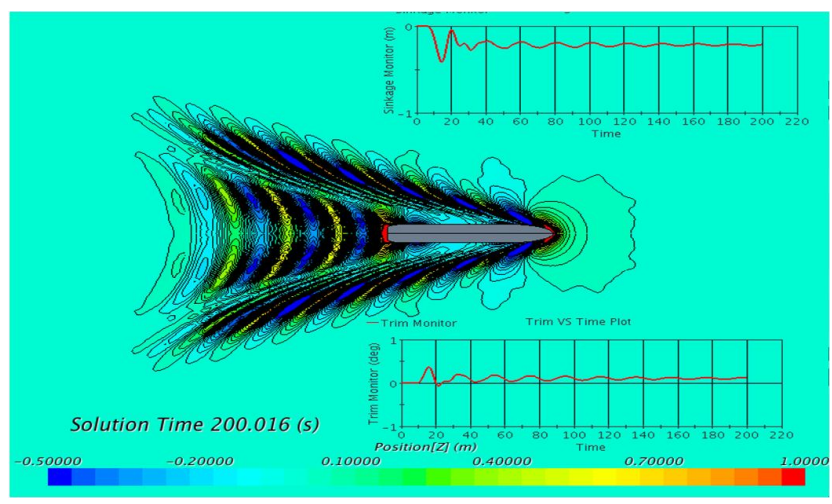

Figure 12 - Wave Pattern Along With Trim And Sinkage Graph For Velocity of $8.5 \mathrm{~m} / \mathrm{s}$
Figure 10 and Figure 11 shows the streamlines along the length of vessel at $F n=0.24$. The wake pattern is clearly visible in Figure 11 and Figure 12 show the wave pattern along with trim and sinkage graph for velocity of $8.5 \mathrm{~m} / \mathrm{s}$. Figure 13 shows the wave patterns at Froude number 0.15 and 0.24 where the velocity is minimum and maximum. The figure clearly shows the effect of velocity on wave pattern.

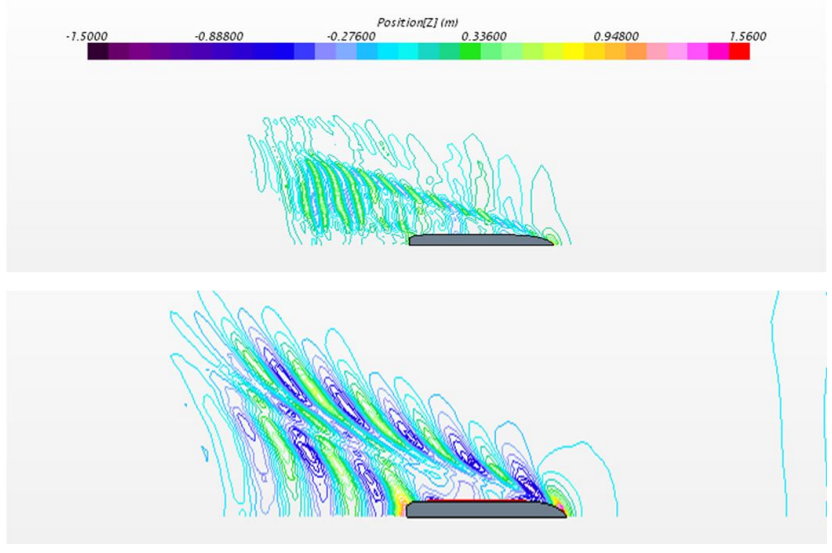

Figure 13 - Wave Pattern at Minimum and Maximum Velocity

\section{CONCLUSIONS}

CFD analysis for a container ship at various Froude numbers with and without trim and sinkage has been performed using Star CCM+ software. The two turbulence models considered are Realizable $k-\varepsilon$ turbulent model and SST $k-\omega$ turbulent model. The results indicate that the total resistance predicted using the CFD software matches very closely with the empirical method such as Holtrop and Mennen Method. No comparisons were made for the case where trim and sinkage are considered.

Dependence of the solution on the mesh was also carried out and it is found that the predicted values did not change beyond $6 \%$ from that predicted for smaller meshes at an expense of nearly $300 \%$ computational time. Resistance values obtained using a mesh of $2.7 \mathrm{M}$ were more closer to the empirical formula compared to mesh with $2.1 \mathrm{M}$ cells with a slight computational overhead. This mesh size is taken as optimum and all further computations where performed with this mesh size The two turbulence models considered namely Realizable $k-\varepsilon$ turbulent model and SST $k-\omega$ turbulent model predicted the results with the same order of magnitude. Generally it is observed that the Realizable k- $\varepsilon$ model predicted a higher resistance value while the SST k- $\omega$ model predicted a lower value compared to the empirical methods.

\section{REFERENCES}

[1] Stern, F., "Effects of Waves on the Boundary Layer of a Surface-Piercing Body," Journal of Ship Re-search, 1986, Vol. 30, No. 4, pp. 256-274. 
[2] Pranzitelli, A., Nicola, C.de., and Miranda, S., "steadystate calculations of free surface flow around ship hulls and resistance," 2011, IX HSMV Naples.

[3] Banks, J., Phillips, A., and Turnock, S., "Free surface CFD prediction of components of ship resistance for KCS," $13^{\text {th }}$ Numerical Towing Tank Symposium, Germany 2010, pp.17.3 .

[4] Salina Aktar., Goutam Kumar Saha., and Md. Abdul Alim., "Drag analysis of different ship models using Computational Fluid Dynamics tools," The International Conference on Marine Technology, 2010, 11-12 December, BUET, Dhaka, Bangladesh.

[5] Hirt, C.W., and Nichols, B.D., "Volume of Fluid (VOF) Method for the Dynamics of Free Boundaries," Journal of Computational Physics, 1979, Vol 39, Page 201-225.
[6] Holtrop, J., and Mennen, G.G.J., "An Approximate Power Prediction Method." 1982,

[7] Harvald, S.V.A.A., "Resistance and propulsion of ships" by, Department of ocean Engineering, The Technical University of Denmark.

[8] John, D., Anderson, "Computational Fluid Dynamics -The Basics with Applications" by Department of Aerospace Engineering, University of Maryland.

[9] Versteeg, H. K., and Malalasekera, W., "An Introduction to Computational Fluid Dynamics -The Finite Volume Method by," 1995, Prentice Hall, India.

[10] Tupper, E.C., "Introduction to Naval Architecture," Four Edition.

[11] User Guide version STAR-CCM+ 9.04. 